\title{
A Putative ECF $\sigma$ Factor Gene, rpol, Regulates Siderophore Production in Rhizobium leguminosarum
}

\author{
Kay H. Yeoman, Alex G. May, Nicola G. deLuca, Daniel B. Stuckey, and Andrew W. B. Johnston \\ School of Biological Sciences, University of East Anglia, Norwich NR4 7TJ, U.K. \\ Accepted 15 July 1999.
}

\begin{abstract}
A cloned Rhizobium leguminosarum gene, termed rpoI, when transferred to wild-type strains, caused overproduction of the siderophore vicibactin. An rpoI mutant was defective in $\mathrm{Fe}$ uptake but was unaffected in symbiotic $\mathrm{N}_{2}$ fixation. The RpoI gene product was similar in sequence to extra-cytoplasmic $\sigma$ factors of RNA polymerase. Transcription of rpoI was reduced in cells grown in medium that was replete with Fe.
\end{abstract}

Additional keywords: ccm, nodules, peas.

Although Fe is abundant, its extreme insolubility in the ferric form at neutral and alkaline $\mathrm{pH}$ makes it hard for cells to obtain sufficient amounts of the metal. Many microbes make siderophores, low $M_{\mathrm{r}}$ compounds that bind $\mathrm{Fe}^{3+}$ and the siderophore- $\mathrm{Fe}^{3+}$ complex is internalized by dedicated transporters (Braun et al. 1998; Crosa 1997). $\mathrm{N}_{2}$-fixing bacteria have a particularly high demand for this metal, since nitrogenase and ancillary electron donors contain $\mathrm{Fe}$ in their co-factors. Symbiotic bacteria known as rhizobia fix $\mathrm{N}_{2}$ in legume nodules, where there is an extra Fe demand by the plant, since the abundant leghemoglobin contains heme (Fett et al. 1998). Rhizobium leguminosarum bv. viciae, the symbiont of peas, makes a siderophore called vicibactin, a cyclic tri-hydroxamate with three moieties each of D-hydroxybutyrate and $\mathrm{N}^{2}$-acetyl- $\mathrm{N}^{5}$-hydroxy-D-ornithine, joined in alternate peptide and ester bonds (Dilworth et al. 1998). Other rhizobia make different siderophores including catechols (Roy et al. 1994) and rhizobactin (Persmark et al. 1993). The role of individual siderophores in the symbiosis is unclear. Some mutants $\left(\mathrm{Sid}^{-}\right)$that are defective in the synthesis or uptake of siderophore are unaffected in symbiotic $\mathrm{N}_{2}$ fixation (Reigh and O'Connell 1993; Stevens et al. 1999) but others are Fix $^{-}$(e.g., Barton et al. 1996b; see Yeoman et al. 1997; see below).

In $R$. leguminosarum bv. viciae, we identified homologues of some of the $f h u$ genes that specify proteins that import hydroxamate siderophores (Stevens et al. 1999). Expression of fhuDCB was enhanced in cells grown in low Fe growth conditions. In Bradyrhizobium japonicum, expression of an outer membrane protein, FegA, a homologue of the Escherichia coli receptor FhuA, was also higher in bacteria grown in low $\mathrm{Fe}$ conditions (LeVier and Guerinot 1996). Although mutations in fhuDCB virtually abolished the ability of $R$. leguminosarum to

Corresponding author: A. W. B. Johnston

E-mail: a.johnston@uea.ac.uk take up vicibactin, no noticeable effects on symbiotic $\mathrm{N}_{2}$ fixation were found. This raises the question of how is it that the bacteroids in the nodule obtain their large supplies of Fe (Fett et al. 1998).

In bacteria, expression of the Fe uptake system is regulated. In many bacteria, the product of the "global" regulator, fur, binds to promoters of many genes that are involved in Fe metabolism (Crosa 1997). A fur homologue was identified in $R$. leguminosarum but it was not possible to isolate fur "knockout" mutants (deLuca et al. 1998), indicating that, as in some other bacteria, fur is essential (Ochsner et al. 1995). Other bacterial transcriptional regulators affect expression of genes involved in Fe uptake. The widely found ECF (extracytoplasmic function) family of $\sigma$ factors usually affect characters involving proteins that occur at the cell surface (Lonetto et al. 1994). In E. coli, FecI is one such $\sigma$ factor, activating fec genes that are involved in Fe-citrate uptake (Enz et al. 1995). In Pseudomonas putida, PupI appears to be an ECF $\sigma$ factor that activates genes for the uptake of the siderophore pseudobactin (Koster et al. 1994).

In $P$. aeruginosa, $P$. putida, and $P$. fluorescens, nearidentical genes, $p v d S$, $p f r I$, and $p b r A$, respectively, are homologues of the ECF family (Callanan et al. 1996; Venturi et al. 1995; Sexton et al. 1995, 1996; Cunliffe et al. 1995; Miyazaki et al. 1995). Mutations in these genes affect synthesis of the siderophores pseudobactin and pyoverdin, and, in the case of $P$. aeruginosa, of exotoxin. The effect on this latter phenotype is mediated by a regulatory cascade in which $p v d S$ regulates transcription of ptxR that, in turn, controls transcription of toxA (Vasil et al. 1998). In $P$. aeruginosa, pvdS positively regulates $\operatorname{reg} A B$, a two-component regulator of siderophore and toxin production genes (Ochsner et al. 1996). $p v d S$ itself is regulated by the fur transcriptional regulator in response to $\mathrm{Fe}$ availability (Barton et al. 1996a; Ochsner et al. 1995; Leoni et al. 1996).

Here, we describe a gene, rpoI, from $R$. leguminosarum that is similar in sequence to the $p v d S / p f r I / p b r A$ genes of Pseudomonas spp. and that affects siderophore production and $\mathrm{Fe}$ uptake in $R$. leguminosarum.

\section{RESULTS AND DISCUSSION}

Identification of a cosmid causing overproduction of siderophore.

A gene bank (deLuca et al. 1998), consisting of DNA of the $R$. leguminosarum bv. viciae strain $8401 \mathrm{pRL} 1 \mathrm{JI}$ cloned in the wide-host-range cosmid pLAFR1, was mobilized en masse 
into strain $8401 \mathrm{pRL} 1 J \mathrm{~J}$. Transconjugants were picked to CAS indicator plates; one (of 800 picked) made a larger halo than normal (Fig. 1). DNA of the plasmid (termed pBIO1096) was isolated from this strain and introduced into $E$. coli, then retransferred to $R$. leguminosarum; the transconjugants again overproduced siderophore on CAS plates.

\section{Identification of rpoI.}

To identify the gene that was responsible for vicibactin overproduction, pBIO1096 was partially digested with EcoRI (the gene library was made with EcoRI-digested Rhizobium genomic DNA), followed by religation. The resultant plasmids were mobilized into $R$. leguminosarum and plasmid DNA was isolated from transconjugants that overproduced siderophore on CAS plates. These were transformed into the E. coli strain 803 and examined on gels following EcoRI digestion; all shared a 4.5-kb EcoRI fragment. One of these deleted plasmids was termed pBIO1114. Following subcloning into the broad-host-range vector pRK415, and transfer into $R$. leguminosarum, it was found that the gene(s) causing siderophore overproduction was within a 1.2-kb ClaI fragment.

This fragment was sequenced in both orientations. It contained one intact ORF (open reading frame), which we term rpoI, with a sequence of relevance to the phenotype conferred by this cloned DNA (Fig. 2). The rpoI product is most similar to those of $p v d S$, pfrI, and pbrA of $P$. aeruginosa, $P$. putida, and $P$. fluorescens, respectively. These genes are very similar to each other and are involved in positively regulating siderophore production (Cunliffe et al. 1995; Sexton et al. 1995; Venturi et al. 1995). They are, themselves, homologues of the ECF family of $\sigma$ factors, though it was not directly demonstrated that they are constituents of

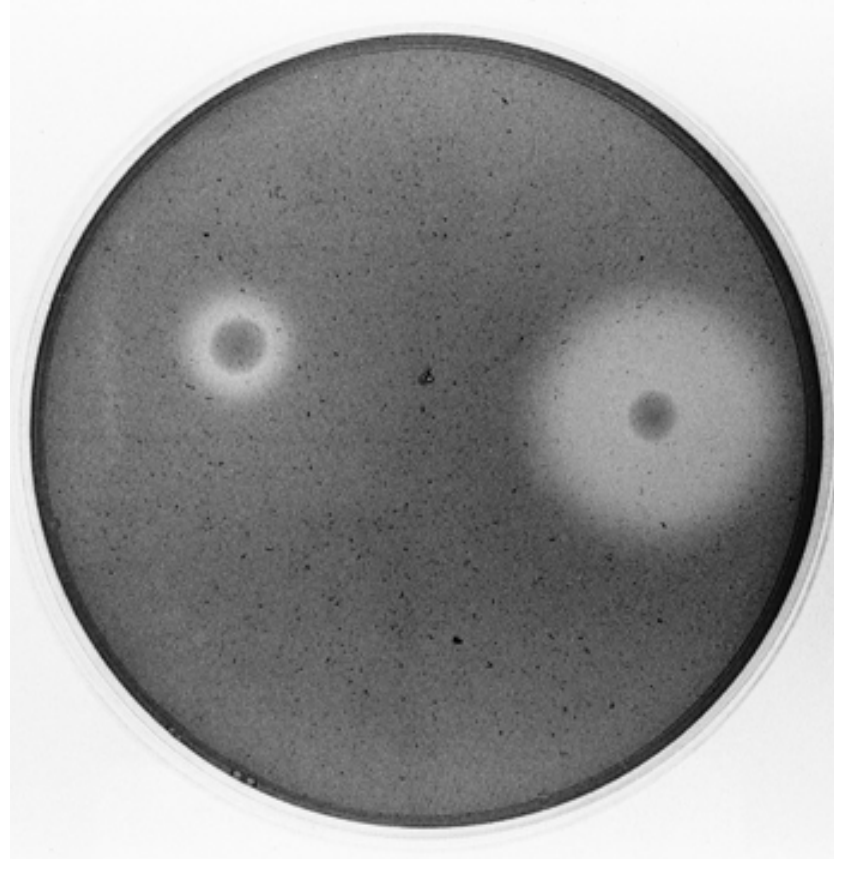

Fig. 1. Production of siderophore on chrome azurol sulfonate (CAS) plates. (Left) Rhizobium leguminosarum wild type and (right) transconjugant containing rpoI in pBIO1062.
RNA polymerase. It was noted (Ochsner et al. 1996) that when $p v d S$ was cloned and introduced into a wild-type strain of $P$. aeruginosa, these bacteria overproduced siderophore.

The sequence of the RpoI protein is much more similar to $\mathrm{PvdS/PfrI} / \mathrm{PbrA}$ of Pseudomonas spp. than to other members of the ECF family and the homology was far greater in the Cterminal half of the proteins than elsewhere (Fig. 2). In the Nterminal half of the protein there was less similarity in sequence to the "PvdS" proteins or to other members of the ECF family. However, there was limited identity of sequence between RpoI and FecI (Fig. 2), which in E. coli is a proven $\sigma$ factor that regulates genes involved in $\mathrm{Fe}^{3+}$-citrate uptake. In many cases, ECF $\sigma$ factors have anti- $\sigma$ factors that modulate their activity and often the gene specifying the anti- $\sigma$ factor is adjacent to the gene for the ECF $\sigma$ factor (see Missiakis and Raina 1998). However, there was no gene with homology to any sequence in data bases within the sequenced region in the $431 \mathrm{bp} 5^{\prime}$ of rpoI. It remains to be established if there is an authentic short ORF in this upstream region. In the region $3^{\prime}$ of rpoI and in the opposite orientation, were 218 bp of the $3^{\prime}$ end of an ORF whose product is similar to cystathionine- $\gamma$ synthase, the product of bacterial metB genes. The closest similarity was to MetB of Helicobacter pylorii (44\% identical). Surprisingly, there was an overlap, of $94 \mathrm{bp}$, between the $3^{\prime}$ ends of rpoI and metB.

\section{Partial suppression of $\mathrm{ccm}$ mutants by cloned $r$ poI.}

Yeoman et al. (1997) found that $R$. leguminosarum strains that were mutated in the $c y c H J K L$ operon were defective in Fe uptake and in the production of vicibactin. The primary role of these genes, now known as $c \mathrm{~cm}$, is in the maturation of $c$-type cytochromes (see Thony-Meyer 1997); it is unclear why $\mathrm{ccm}$ mutations affect siderophore production. This phenotype was also observed in Pseudomonas fluorescens and Paracoccus thiospaera (Gaballa et al. 1996; Pearce et al. 1998), in which ccm mutants are defective in siderophore synthesis. In $P$. putida, ccmF mutants overproduce siderophore (deVrind et al. 1998).

To see if cloned rpoI suppressed the phenotype(s) of a $\mathrm{ccm}$ mutant of $R$. leguminosarum, pBIO1114 was mobilized into strain A266, which has a $c y c K(c c m F)$ mutation (Yeoman et al. 1997). The transconjugant made a halo on CAS plates that was approximately the same size as that of the wild-type strain; i.e., larger than the barely discernible halo of the $\mathrm{ccm}$ mutant but smaller than that of wild-type $R$. leguminosarum containing pBIO1114.

Mutant A266 is also defective in $\mathrm{Fe}^{3+}$ uptake (Yeoman et al. 1997); pBIO1114 also corrected this phenotype (not shown). Transconjugants were treated with dimethylphenylenediamine (NADI), which stains cells for $c$-type cytochromes. In contrast to the siderophore production and the $\mathrm{Fe}^{3+}$ uptake phenotypes, this defect was not corrected, the colonies giving no staining reaction with NADI.

Some mutations in ccmC of $P$. fluorescens severely affected siderophore production but had little effect on cytochrome $c$ maturation-and vice versa for other $\mathrm{ccmC}$ alleles (Gaballa et al. 1998). That observation, together with our finding that siderophore production but not cytochrome $c$ maturation was suppressed by introducing cloned rpoI, indicates that the $\mathrm{ccm}$ genes may affect these two phenotypes in two, perhaps independent, ways. 


\section{Iron-dependent expression of rpoI.}

In Pseudomonas spp., expression of $p v d S$ is repressed by Fe. To examine the expression of rpol, pBIO1114 was mutagenized with transposon Tnlac and derivatives no longer causing overproduction of siderophore on CAS plates were sought. Two mutant plasmids, pBIO1105 and pBIO1106, were obtained. The insertions in both plasmids were located in the coding region of rpoI, the insertion in pBIO1106 being oriented such that rpoI and lacZ of Tnlac were in the same direction; in pBIO1105, rpoI and lacZ were in opposite orientations. Sequencing the junctions of Tnlac insertions and the Rhizobium DNA showed that in pBIO1105 and pBIO1106 they were located, respectively, 7 and 252 bp downstream of the translational start of rpoI.

The two plasmids were mobilized into R. leguminosarum. Transconjugants were grown in high and low Fe media and were assayed for $\beta$-galactosidase. The levels of activity from
pBIO1106 were approximately eightfold greater in bacteria starved of Fe. In Fe-replete medium values of $807 \pm 46$ were obtained; when Fe was removed, the $\beta$-galactosidase activities were $5,780 \pm 86$. As expected, the strain with pBIO1105 (lacZ in the "wrong" orientation) had barely detectable $\beta$-galactosidase ( $<50 \mathrm{U}$ in both growth media).

In $P$. aeruginosa, transcription of $p v d S$ is regulated by fur in an Fe-dependent way. It was impossible to get a fur mutant in $R$. leguminosarum (deLuca et al. 1998) so we could not test if rpoI, too, is regulated by fur. In many bacterial genera, Fur protein binds to a short 'fur box' sequence upstream of genes that it regulates. There is a sequence, TGActcTtgTTATC 130 bp upstream of rpoI, in which capitals represent bases matching the fur box consensus (Crosa 1997). Usually, fur boxes have dyad symmetry (although see Calderwood and Mekalanos 1987) and it is thought that Fur binds to them as a dimer. The sequence above is not symmetric, the best match being to

\begin{tabular}{|c|c|c|c|c|}
\hline$\nabla$ & * & $\star \star$ & & \\
\hline MHTLHRDVN- & -GNAVVNAMI & ENKEKLLKTI & ESVVKSKSYS & RpoI \\
\hline MTE-QVSTSK & CDSPLLHAEV & DNRLIĒVKIA & A $\bar{R} I T G C R S R A$ & PbrA \\
\hline MAE-QLLSTSK & CDSPLLQAEV & DNRSILVKIA & ARITGCRSRA & PfrI \\
\hline MSE-QLSTRR & CDTPLLQAEV & DNRT ILVKIA & ARITGCRSRA & Pvds \\
\hline$\star \star$ & * & * * & 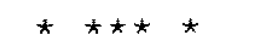 & \\
\hline EDIFQDGVIK & AYGVK--TDG & IRCPIGYAER & MVYNLALDES & RpoI \\
\hline ED̄VV̄QDAFFR & LQSAPPITSS & $\overline{I K} A \bar{Q} L S Y L F Q$ & IVRNLAI $\bar{D} H Y$ & $\mathrm{Pbr} A$ \\
\hline EDVVQDAFFR & LSAAPQITSS & FKAQLSYLEQ & IVRNLAIDHY & PfrI \\
\hline EDVVQDAFFR & LQSAPQITSS & FKAQLSYLFQ & IVRNLAIDHY & PvdS \\
\hline $\boldsymbol{\nabla}$ & & * & $\star$ & \\
\hline RRRRQQMNNY & RSIDQVQE-- & ITAPIPTVLD & QLVAAETLRN & RpoI \\
\hline RKQALEQKYS & GPEEEGLNVV & IQGAS $\bar{P} E--T$ & SHINESTLEN & PbrA \\
\hline RKQAMELKYS & GSEEEGLNVV & IQNASPE- - A & THINLAALDE & PfrI \\
\hline RKQALEQKYS & GPEEEGLNVV & IQGASPE--T & SHINYATLEH & PvdS \\
\hline
\end{tabular}

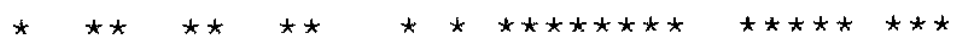

VLASLEALPK RTNDAFIRHR LNGVPQKDIA AELGVSRTLV RPOI

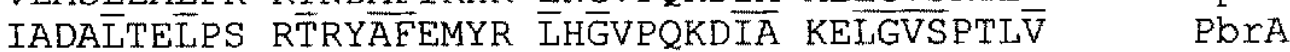

IAEALNELPQ RTRSAFEMYR LHGVPQKDIA KELGVSPTLV PfII

IADALTELPK RTRYAFEMYR LHGVPQKDIA KELGVSPTLV PVdS

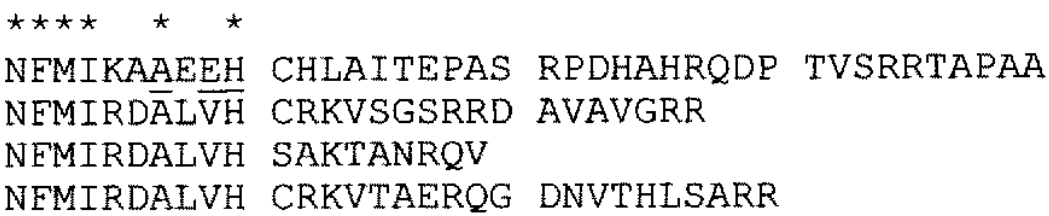

NHSTTVPALP DQRRTEPSAR SHRTG
RpoI

Fig. 2. Comparison of RpoI protein of Rhizobium leguminosarum with PvdS, PbrI, and PfrI of Pseudomonas spp. Asterisks show residues that are identi$\mathrm{cal}$ in all four proteins. Underlined residues in the RpoI sequence indicate those that are identical in FecI of Escherichia coli. Arrows indicate the sites corresponding to the insertions of Tnlac in mutant plasmids pBIO1105 and pBIO1106. 
only one "half" of the fur box consensus. A speculative possibility is that the sequence is regulatory but is recognized by a heterodimer, one component of which is Fur, the other being an unknown protein that binds to the $5^{\prime}$ half of the sequence.

Yeoman et al. (1997) identified two $R$. leguminosarum genes, feuP and feu $Q$, that are homologues of the two-component family of regulators. Mutations in $f e u Q$ reduce Fe uptake, but siderophore production is unaffected. To see if feuQ affected transcription of rpoI, the lac-fusion plasmid pBIO1106 was mobilized into $f e u Q$ mutant $\mathrm{J} 100$ and transconjugants were grown in medium supplemented with or depleted of $\mathrm{Fe}$ before $\beta$-galactosidase was measured. The results were similar to those with pBIO1106 in the wild type; expression was depressed, to the same extent, in cells grown with Fe, compared with those with di-pyridyl (not shown).

\section{Isolation of an rpoI mutant.}

Mutant plasmid pBIO1105 was introduced into R. leguminosarum bv. viciae wild-type $8401 \mathrm{pRL} 1 \mathrm{JI}$ and, following introduction of the P1-group plasmid pPH1JI, derivatives that were $\operatorname{Kan}^{\mathrm{r}}(\mathrm{Tn} l a c), \mathrm{Gent}^{\mathrm{r}}$ (pPH1J), and Tet ${ }^{\mathrm{s}}$ (pLAFR1) were picked to CAS plates in the anticipation that rpoI mutants would be defective in siderophore synthesis. One such $\mathrm{CAS}^{-}$ derivative (termed J255) was kept for further study; it was

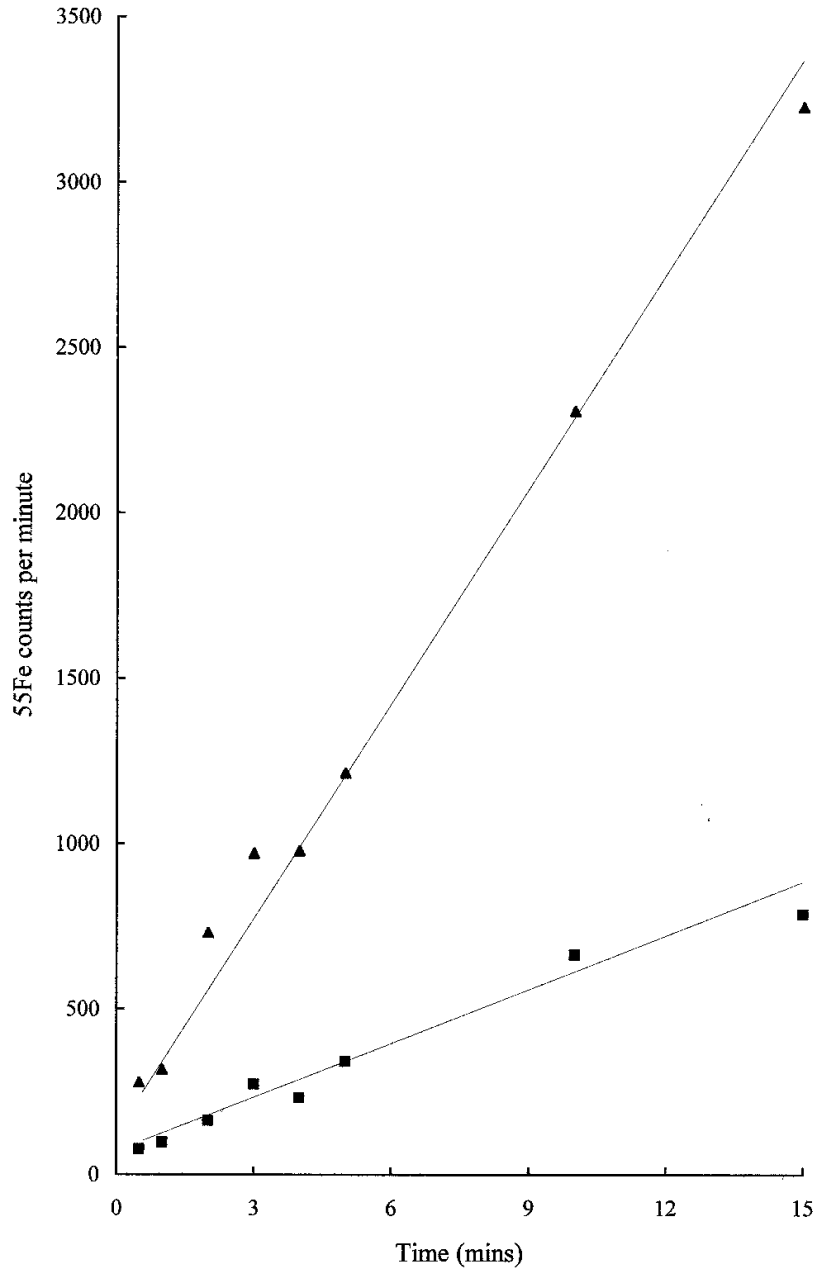

Fig. 3. Uptake of ${ }^{55} \mathrm{Fe}$ by wild-type Rhizobium leguminosarum (triangles) and the rpoI mutant J255 (squares). confirmed by Southern blots that Tnlac was in the chromosomal copy of rpoI in this homogenote.

\section{Effect of rpoI on vicibactin production.}

To quantify the Fe-binding hydroxamate made by strains carrying pBIO1114, liquid cultures of strain 8401pRL1JI and a derivative with the plasmid were grown in minimal media and hydroxamates were assayed. Cells were grown in medium depleted for available Fe. The presence of pBIO1114 caused an approximately fourfold increase in the concentrations of hydroxamate (170 $\mu \mathrm{M}$ desferal equivalents, compared with 42 $\mu \mathrm{M}$ in the control wild type).

The only known siderophore in wild-type $R$. leguminosarum is vicibactin (Dilworth et al. 1998). To identify the hydroxamate in strains harboring pBIO1114, enriched aqueous extracts of supernatant (Carson et al. 1992) were analyzed by electro-spray mass spectrometry (ESMS). For those in which vicibactin was extracted at acid (5.0) $\mathrm{pH}$, in the presence of $\mathrm{Fe}^{3+}$, extracts from both strains had a molecule of $M_{\mathrm{r}} 850$, corresponding to that of Fe-vicibactin (Dilworth et al. 1998) plus a single $\mathrm{Na}^{+}$ion. There was approximately four times more of this material from the strain with pBIO1114 than in the control. For the preparation obtained at $\mathrm{pH} 8.0$, in the absence of $\mathrm{Fe}^{3+}$, this spike was replaced by one $\left(M_{\mathrm{r}} 797\right)$, corresponding to the expected size of $\mathrm{Na}^{+}$-charged vicibactin lacking $\mathrm{Fe}$ but with, instead, three protons. No other peak in the spectrum was altered in its apparent $M_{\mathrm{r}}$ in response to changes in $\mathrm{pH}$ or the presence of $\mathrm{Fe}^{3+}$. Thus, pBIO1114 increases the production of vicibactin, rather than of a novel molecule.

In similar experiments, it was found that the rpoI mutant J255 made approximately 5\% the quantities of vicibactin, compared with the wild-type 8401pRL1JI.

\section{Effect of rpoI on $\mathrm{FeCl}_{3}$ uptake.}

Strains 8401pRL1JI, a derivative containing pBIO1114, and mutant $\mathrm{J} 255$ were examined for their uptake of ${ }^{55} \mathrm{FeCl}_{3}$. The presence of the cloned rpoI caused a significantly greater rate of uptake, due presumably to the higher amounts of vicibactin (not shown). This, together with results shown below, indicates that, under these conditions, the "limiting factor" for $\mathrm{Fe}$ uptake is the amount of the siderophore in the extracellular medium rather than the rate at which the Fe-vicibactin complex is internalized.

In contrast, with the rpoI mutant strain $\mathrm{J} 255$, the levels of Fe uptake were significantly reduced, compared with wild type (Fig. 3).

\section{Effects of rpoI on expression of the fhuDCB genes.}

Stevens et al. (1999) identified an operon, fhuDCB in $R$. leguminosarum, that encoded homologues of the Fhu proteins that, in E. coli and other bacteria, are involved in uptake of hydroxamates. Transcription of $f h u D C B$ was higher, by approximately 10 -fold in Fe-starved bacteria than in those that were replete with Fe (Stevens et al. 1999). To see if rpoI affected expression of fhuDCB, pBIO403, which contains an fhuB::lac fusion, was mobilized into the rpoI mutant strain J255 and into the wild-type control. These strains were grown in high and low Fe minimal medium and it was found that the rpoI mutation had no detectable effect on expression of the $f h u B$ fusion; in both backgrounds, $\beta$-galactosidase activities were approximately eightfold higher in low than in high $\mathrm{Fe}$ 
media and the absolute levels of activities were similar in the corresponding media (182 and $211 \mathrm{U}$, respectively, for wildtype and $\mathrm{J} 255$ backgrounds in high Fe medium and 1,456 and 1,511 $\mathrm{U}$ in low Fe media).

\section{Effect of rpoI on symbiotic $\mathbf{N}_{\mathbf{2}}$ fixation.}

Peas were inoculated with strain J255. As judged by the numbers, sizes, and times of appearance of the nodules, this rpoI mutant was very similar to the wild type. Bacteria were isolated from the nodules and a number of them were examined; in all cases they were $\operatorname{Kan}^{\mathrm{r}}$ and had very small halos on CAS indicator plates. Thus, rpoI does not appear to be essential for nodulation or $\mathrm{N}_{2}$ fixation.

\section{Conclusions.}

Many of the proposed ECF $\sigma$ factors were identified by amino acid sequence homologies (Missiakis and Raina 1998). On this basis, rpoI of $R$. leguminosarum appears to be another member of this group of transcriptional regulators. The similarity is by far the greatest to the PvdS/PbrI/PfrI proteins of Pseudomonas spp., which affect expression of genes involved in siderophore uptake in that genus. The similarity of RpoI to these three Pseudomonas spp. gene products is largely confined to their C-terminal halves; elsewhere, there is more limited amino acid sequence similarity and that which is observed is in regions in which PvdS, PbrI, and PfrI are also similar to regions of other ECF proteins, such as FecI. This suggests that the C-terminal half of these proteins constitute a discrete domain that in R. leguminosarum and Pseudomonas spp. may have matching functions.

rpoi mutants are defective in both Fe uptake and in the synthesis of vicibactin. Conversely,. strains with cloned rpoI produce more vicibactin and exhibit an enhanced rate of $\mathrm{Fe}$ uptake. These observations suggest that the proposed RpoI $\sigma$ factor affects more than one set of genes involved in the cells' ability to make and/or process vicibactin. There was no detectable effect of rpoI on expression of the fhuBCD uptake genes. Further work is needed to identify those genes that are involved in vicibactin synthesis and others that specify its uptake to determine if activation of these is directly regulated by rpoI.

The rpoI mutant strain $\mathrm{J} 255$ could nodulate and fix $\mathrm{N}_{2}$ on peas. This indicates that, whatever genes are regulated by rpol, they are not needed for symbiotic $\mathrm{N}_{2}$ fixation. This is consistent with earlier work showing that $f h u$ mutants that are completely defective in vicibactin uptake are unaffected in the symbiosis (Stephens et al. 1999) and points to the possibility that rhizobia may have different mechanisms for the acquisition of $\mathrm{Fe}$ in the nodule.

\section{MATERIALS AND METHODS}

\section{Microbiological and genetic techniques.}

Growth conditions for E. coli and R. leguminosarum were as in Beringer (1974). Plasmids were transferred by conjugation with pRK2013 as helper plasmid (Figurski and Helinski 1979). Mutagenesis of pBIO1096 with Tnlac (Simon et al. 1989) and marker exchange into the Rhizobium genome with pPH1JI as the P1 incompatibility plasmid to eliminate pBIO1096 were as described by Downie et al. (1983). $\beta$ Galactosidase activities were done as in Rossen et al. (1985).
Bacteria were grown either in minimal media containing $\mathrm{FeCl}_{3}(20 \mu \mathrm{M})$ or, in low Fe media, with no added Fe but with $20 \mu \mathrm{M}$ di-pyridyl. Peas (cv. Frisson) were inoculated and assayed for $\mathrm{N}_{2}$ fixation as in Beynon et al. (1980).

\section{Siderophore assays and Fe uptake measurements.}

Plate tests (Yeoman et al. 1997) used chrome azurol sulfonate (CAS) stain (Schwyn and Neilands 1987). Trihydroxamates in culture supernatants were assayed as in Carson et al. (1992). Vicibactin was identified by ESMS in a VG Platform spectrometer (Fisons PLC, Altringham, U.K.).

Ferric ${ }^{55} \mathrm{Fe}$ uptake was measured as described by Yeoman et al. (1997).

\section{DNA manipulations}

Routine DNA manipulations were done as in Downie et al. (1983); the E. coli strain 803 (Wood 1966) was used for transformation with large plasmids. DNA sequencing was performed commercially by MWG (Munich) by the dideoxychain termination method.

\section{ACKNOWLEDGMENTS}

We are grateful to Rick Evans-Gowing for skilled technical assistance. This work was supported in part by the BBSRC of the U.K.

\section{LITERATURE CITED}

Barton, H. A., Johnson, Z., Cox, C. D., Vasil, A. I., and Vasil, M. L. 1996a. Ferric uptake mutants of Pseudomonas aeruginosa with distinct alterations in the iron-dependent repression of exotoxin-A and siderophores in aerobic and microaerobic environments. Mol. Microbiol. 21:1001-1017.

Barton, L. L., Johnson, G. V., Schitoskey, K., and Wertz, M. 1996b. Siderophore-mediated iron metabolism in growth and nitrogen fixation by alfalfa nodulated with Rhizobium meliloti. J. Plant Nutr. 18:12011219.

Beringer, J. E. 1974. R factor transfer in Rhizobium leguminosarum. J. Gen. Microbiol. 84:188-198

Beynon, J. L., Beringer, J. E., and Johnston A. W. B. 1980. Plasmids and host-range in Rhizobium leguminosarum and Rhizobium phaseoli. J. Gen. Microbiol. 120:421-429.

Braun, V., Hantke, K., and Koster, W. 1998. Bacterial iron transport: mechanisms, genetics, and regulation. Metal Ions Biol. Sys. 35:67145.

Calderwood, S., and Mekalanos, J. 1987. Iron regulation of shiga-like toxin expression in Escherichia coli is mediated by the fur locus. J. Bacteriol. 169:4759-4764.

Callanan, M., Sexton, R., Dowling, D. N., and O'Gara, F. 1996. Regulation of the iron uptake genes in Pseudomonas fluorescens M114 by pseudobactin M114 - the PbrA sigma factor gene does not mediate the siderophore regulatory response. FEMS Microbiol. Lett. 144:61-66.

Carson, K. C., Dilworth, M. J., and Glenn, A. R. 1992. Siderophore production and iron transport in Rhizobium leguminosarum. J. Plant Nutr. 15:2203-2220.

Crosa, J. H. 1997. Signal transduction and transcriptional and posttranscriptional control of iron-regulated genes in bacteria. Microbiol. Mol. Biol. Rev. 61:319-341.

Cunliffe, H. E., Merriman, T. R., and Lamont, I. L. 1995. Cloning and characterization of $p v d S$, a gene required for pyoverdine synthesis in Pseudomonas aeriginosa - pvdS is probably an alternative sigma factor. J. Bacteriol. 177:2744-2750.

deLuca, N. G., Wexler, M., Pereira, M. J., Yeoman, K. H., and Johnston, A. W. B. 1998. Is the fur gene of Rhizobium leguminosarum essential? FEMS Microbiol. Lett. 168:289-295.

deVrind, J. P. M., Brouwers, G. J., Corstjens, P. L. A. M., den Dulk, J., and deVrinddeJong, E. W. 1998. The cytochrome $c$ maturation operon is involved in manganese oxidation in Pseudomonas putida GB-1. 
Appl. Environ. Microbiol. 64:3556-3562.

Dilworth, M. J., Carson, K. C., Giles, R. G. F., Byrne, L. T., and Glenn, A. R. 1998. Rhizobium leguminosarum bv. viciae produces a novel cyclic trihydroxamate siderophore, vicibactin. Microbiology 144:781791.

Downie, J. A., Hombrecher, G., Ma, Q. S., Knight, C. D., Wells, B., and Johnston, A. W. B. 1983. Cloned nodulation genes of Rhizobium leguminosarum determine host-range specificity. Mol. Gen. Genet. 190: 359-265.

Enz, S., Braun, V., and Crosa, J. H. 1995. Transcription of the region encoding the ferric dicitrate-transport system in Escherichia coli: Similarity between promoters for $\mathrm{fecA}$ and extrachromosomal sigma factors. Gene 163:1462-1471.

Fett, J. P., LeVier, K., and Guerinot, M. L. 1998. Soil microorganisms and iron uptake by higher plants. Metal Ions Biol. Sys. 35:188-214.

Figurski, D. H., and Helinski, D. R. 1979. Replication of an origincontaining derivative of plasmid RK2 dependent on a plasmid function provided in trans. Proc. Natl. Acad. Sci. USA 76:1648-1652.

Gaballa, A., Baysse, C., Koedam, N., Muyldermans, S., and Cornelis, P. 1998. Different residues in periplasmic domains of the $\mathrm{CcmC}$ inner membrane protein of Pseudomonas fluorescens ATCC 17400 are critical for cytochrome $c$ biogenesis and pyoverdine-mediated iron uptake. Mol. Microbiol. 30:547-555.

Gaballa, A, Koedam, N, and Cornelis, P. 1996. A cytochrome $c$ biogenesis gene involved in pyoverdine production in Pseudomonas fluorescens ATCC 17400. Mol. Microbiol. 4:777-785.

Koster, M., van Klompenburg, W., Bitter, W., Leong, J., and Weisbeek, P. 1994. Role for the outer-membrane ferric siderophore receptor PupB in signal transduction across the bacterial cell envelope. EMBO J. 13: 2805-2813.

Lamb, J. W., Hombrecher, G., and Johnston, A. W. B. 1982. Plasmiddetermined nodulation and nitrogen-fixation abilities in Rhizobium phaseoli. Mol. Gen. Genet. 186:449-452.

Leoni, L., Ciervo, A., Orsi, N., and Visca, P. 1996. Iron-regulated transcription of the pvdA gene in Pseudomonas aeruginosa - effect of fur and $p v d S$ on promoter activity. J. Bacteriol. 178:2299-2313.

LeVier, K., and Guerinot, M. L. 1996. The Bradyrhizobium japonicum $f e g A$ gene encodes an iron-regulated outer-membrane protein with similarity to hydroxamate-type siderophore receptors. J. Bacteriol. 178:7265-7275.

Lonetto, M., Brown, K. L., Rudd, K. E., and Buttner, M. J. 1994. Analysis of the Streptomyces coelicolor sigmaE gene reveals the existence of a subfamily of eubacterial RNA polymerase sigma factors involved in the regulation of extracytoplasmic functions. Proc. Natl. Acad. Sci USA 91:7573-7577.

Missiakis, D., and Raina, S. 1998. The extracytoplasmic sigma factors: Role and regulation. Mol. Microbiol. 28:1059-1066.

Miyazaki, H., Kato, H., Nakazawa, T., and Tsuda, M. 1995. A positive regulatory gene, $p v d S$, for expression of pyoverdin biosynthetic genes in Pseudomonas aeruginosa. Mol. Gen. Genet. 248:17-24.

Ochsner, U. A., Johnson, Z., Lamont, I. L., Cunliffe, H. E., and Vasil, M. J. 1996. Exotoxin-A production in Pseudomonas aeruginosa requires the iron-regulated $p v d S$ gene encoding an alternative sigma factor. Mol. Microbiol. 21:1019-1028.

Ochsner, U. A., Vasil, A. I., and Vasil, M. 1995. Role of ferric uptake regulator of Pseudomonas aeruginosa in the regulation of siderophores and exotoxin A expression - purification and activity on iron- regulated promoters. J. Bacteriol. 177:7194-7201

Pearce, D. A., Page, M. D., Norris, H. A. C., Tomlinson, E. J., and Ferguson, S. J. 1998. Identification of the contiguous Paracoccus denitrificans $\mathrm{ccmF}$ and $\mathrm{ccmH}$ genes: Disruption of $\mathrm{ccmF}$, encoding a putative transporter, results in formation of an unstable apocytochrome $c$ and deficiency in siderophore production. Microbiology 144:467-477.

Persmark, M., Pittman, P., Buyer, J. S., Schwyn, B., Gill, P. R., and Neilands, J. B. 1993. Isolation and structure of rhizobactin 1021, a siderophore from alfalfa symbiont Rhizobium meliloti 1021. J. Am. Chem. Soc. 115:3950-3956.

Reigh, G., and O'Connell, M. 1993. Siderophore-mediated iron transport correlates with the presence of specific iron-regulated proteins in the outer membrane of Rhizobium meliloti. J. Bacteriol. 175:94-102.

Rossen, L., Shearman, C. A., Johnston, A. W. B., and Downie, J. A. 1985. The nodD gene of Rhizobium leguminosarum is autoregulatory and in the presence of plant root exudate induces the $\operatorname{nod} A B C$ genes. EMBO J. 4:3369-3374.

Roy, N., Bhattacharyya, P., and Chakrabartty, P. K. 1994. Iron acquisition during growth in an iron deficient medium by Rhizobium sp. isolated from Cicer arietinum. Microbiology 140:2811-2820.

Schwyn, B., and Neilands, J. B. 1987. Universal chemical assay for the detection and determination of siderophores. Anal. Biochem. 160:47 56.

Sexton, R., Gill, P. R., Callanan, M. J., O’Sullivan, D. J., Dowling, D. N., and O'Gara, F. 1995. Iron-responsive gene expression in Pseudomonas fluorescens M114 - cloning and characterization of a transcription-activating factor, $p b r A$. Mol. Microbiol. 15:297-306.

Sexton, R., Gill, P. R., Dowling, D. N., and O'Gara, F. 1996. Transcriptional regulation of the iron-responsive sigma-factor gene $\mathrm{pbrA}$. Mol Gen. Genet. 250:50-58.

Simon, R., Quandt, J., and Klipp, W. 1989. New derivatives of transposon $\mathrm{Tn} 5$ suitable for mobilisation of replicons, generation of operon fusions and induction of genes in Gram negative bacteria. Gene 80: 161-169.

Stevens, J. B., Carter, R. A., Hussain, H., Carson, K. C., Dilworth, M. J., and Johnston, A. W. B. 1999. The fhu genes of Rhizobium leguminosarum specifying siderophore uptake proteins; fhuDCB are adjacent to a pseudogene version of fhuA. Microbiology 145:593-601.

Thony-Meyer, L. 1997. Biogenesis of respiratory cytochromes in bacteria. Microbiol. Mol. Biol. Rev. 61:337-379.

Vasil, M. L., Ochsner, U. A., Johnson, Z., Colmer, J. A., and Hamood, A. N. 1998. The fur-regulated gene encoding the alternative sigma factor PvdS is required for iron-dependent expression of the LysRtype regulator PtxR in Pseudomonas aeruginosa. J. Bacteriol. 180; 6784-6788

Venturi, V., Ottevanger, C., Bracke, M., and Weisbeek, P. 1995. Iron regulation of siderophore biosynthesis and transport in Pseudomonas putida WCS358: Involvement of a transcriptional activator and of the fur protein. Mol. Microbiol. 15:1081-1093.

Wood, W. B. 1966. Host specificity of DNA produced by Escherichia coli; bacterial mutations affecting the restriction and modification of DNA. J. Mol. Biol. 16:118-133.

Yeoman, K. H., Delgado, M. J., Wexler, M., Downie, J. A., and Johnston, A. W. B. 1997. High affinity iron acquisition in Rhizobium leguminosarum requires the cycHJKL operon and the feuPQ gene products which belong to the family of two-component regulators. Microbiology 143:127-134. 